\title{
Correlates of Erectile Dysfunction in Nigerian Men with Type 2 Diabetes Mellitus: Experience from a Tertiary Health Center
}

\author{
Chidiebele M. Ezeude ${ }^{*}{ }^{*}$ (), Afoma M. Ezeude², Ekenechukwu E. Young3, \\ Ogonna C. Oguejiofor ${ }^{1}$, Adamu G. Bakari ${ }^{4}$
}

\begin{abstract}
${ }^{1}$ Department of Internal Medicine, Nnamdi Azikiwe University, Awka and Nnamdi Azikiwe University Teaching Hospital, Nnewi, Anambra State, Nigeria

${ }^{2}$ Department of Nursing Science, Faculty of Health Sciences and Technology/School of Postgraduate Studies, Nnamdi Azikiwe University, Nnewi Campus, Nigeria

${ }^{3}$ Department of Medicine, University of Nigeria and University of Nigeria Teaching Hospital, Ituku/Ozalla Enugu State, Nigeria ${ }^{4}$ Department of Internal Medicine, Ahmadu Bello University, Zaria and Ahmadu Bello University Teaching Hospital, Zaria, Kaduna State, Nigeria

Email: *cm.ezeude@unizik.edu.ng, docchidi@yahoo.co.uk
\end{abstract}

\begin{abstract}
How to cite this paper: Ezeude, C.M., Ezeude, A.M., Young, E.E., Oguejiofor, O.C. and Bakari, A.G. (2020) Correlates of Erectile Dysfunction in Nigerian Men with Type 2 Diabetes Mellitus: Experience from a Tertiary Health Center. Journal of Diabetes Mellitus, 10, 182-201.

https://doi.org/10.4236/jdm.2020.103015
\end{abstract}

Received: May 27, 2020

Accepted: August 14, 2020

Published: August 17, 2020

Copyright $\odot 2020$ by author(s) and Scientific Research Publishing Inc. This work is licensed under the Creative Commons Attribution-NonCommercial International License (CC BY-NC 4.0). http://creativecommons.org/licenses/by-nc/4.0/ (c) (i) (3) Open Access

\begin{abstract}
Introduction: Erectile dysfunction (ED) is a common complication of diabetes mellitus (DM) that is associated with poor quality of life and can be present in type 2 diabetics at the time of diagnosis. There are common risk factors associated with erectile dysfunction in type 2 diabetic subjects. Some of these are potentially treatable or reversible. The risk factors evaluated by this study included glycaemic control, duration of diabetes, obesity, peripheral artery disease (PAD), hypertension and antihypertensive medications use. Materials and Methods: This study was a cross sectional one carried out over a period of six months (June-November, 2016) at the diabetes clinic of the Nnamdi Azikiwe University Teaching Hospital, Nnewi and involved 124 subjects with type 2 diabetes mellitus. A convenience sampling method was used. A detailed physical examination, blood pressure and anthropometric measurements and vascular assessment with a hand-held doppler ultrasound were carried out. Data was collected using a study proforma. Erectile dysfunction was diagnosed with the International Index of Erectile Function questionnaire while anxiety and depression were diagnosed with the Hospital Anxiety and Depression questionnaires. Subjects that had anxiety/depression or hypogonadism were excluded from the study. Results: A total of 124 subjects were studied, $48.4 \%$ of whom had erectile dysfunction. Glycaemic control was significantly associated with ED among the subjects $(\mathrm{OR}=0.198,95 \% \mathrm{CI}=0.081$ $0.483, \mathrm{P}<0.001)$. Similarly, peripheral artery disease $(\mathrm{PAD})$ was significantly
\end{abstract}


associated with $\mathrm{ED}$ in the subjects $(\mathrm{OR}=2.867,95 \% \mathrm{CI}=1.360-6.044, \mathrm{P}=$ 0.006). However, no significant correlation was found between ED and obesity, duration of diabetes mellitus, antihypertensive medications use and duration of hypertension among the subjects $(\mathrm{P}>0.05)$. Conclusion: Poor glycaemic control and presence of PAD significantly increase the risk of ED in male subjects with type $2 \mathrm{DM}$, thus underscoring the need for an early screening and treatment of these predictors of erectile dysfunction.

\section{Keywords}

Erectile Dysfunction, Hypogonadism, Type 2 Diabetes, Nigeria, Risk Factors

\section{Introduction}

Erectile dysfunction (ED) is a persistent inability to achieve or maintain erection for satisfactory sexual intercourse and is a predictor of poor quality of life among male diabetic patients [1] [2].

The causes of erectile dysfunction fall into two main categories: organic and psychogenic [3]. The organic causes can be further divided into: vascular, neurological, post traumatic/post-surgical, age-induced, endocrine-induced and drug-induced while the psychogenic causes result mainly from anxiety and depression. Diabetes-induced ED is mainly caused by vasculopathy and neuropathy. A study carried out in Nigeria showed that $7.3 \%$ of cases of erectile dysfunction resulted from diabetes mellitus [4].

The correlates of ED evaluated by this study included glycaemic control, duration of diabetes mellitus, obesity, peripheral artery disease (PAD), hypertension and antihypertensive medications use.

Glycated haemoglobin (HbA1c) is a very reliable surrogate for glycaemic control and reflects the average plasma glucose over the previous 2 - 3 months [5]. Poor glycaemic control results in chronic hyperglycaemia and increases the risk of erectile dysfunction in diabetic subjects through four major hypothetical mechanisms that are linked to vasculopathy and neuropathy. Hyperglycaemiainduced damage to blood vessels and nerves occurs via increased polyol pathway flux, increased intracellular formation of advanced glycation end-products (AGES), activation of protein kinase $\mathrm{C}$ and increased hexosamine pathway flux. All these are linked to over production of superoxide by the mitochondrial transport chain. Superoxide is both vasculopathic and neuropathic.

Notable randomized clinical trials like the UK Prospective Diabetes Study (UKPDS) and Diabetes Control and Complication Trial (DCCT) demonstrated that intensive glycaemic control could substantially reduce microvascular complications of diabetes, but reduction of macrovascular complications was not clear [6] [7]. Statistically significant positive correlation was found between HbA1c and ED in Ghana and Pakistan [8] [9].

Erectile dysfunction has been found to be associated with the duration of di- 
abetes mellitus. Mahbub et al. found a significant positive association between the duration of DM and both the frequency and severity of erectile dysfunction [10].

Overweight and obesity may increase the risk of ED by $30 \%-90 \%$ as compared to normal weight subjects [11]. This could be linked to the development of atherosclerosis and hormonal changes including low testosterone levels that occur in obesity. Statistically significant positive correlation was found between obesity and ED in a study done in Pakistan but not in Italy and Saudi Arabia [9] [12] [13].

Peripheral artery disease is one of the major causes of ED especially in the setting of DM, resulting mainly from generation of toxic and reactive metabolites and accumulation of AGES. A significant positive correlation between PAD and ED was found in China but not in Spain [14] [15]. Some studies have found an association between hypertension and ED in men with type 2 diabetes. Erectile dysfunction is equally the potential side effect of most antihypertensive medications. Older generation antihypertensive drugs (central acting, beta-blockers, diuretics) are mostly implicated [16]. Thiazide diuretics have been the class of antihypertensive drugs mostly implicated in causing erectile dysfunction [16]. Meena et al. found that systolic blood pressure was significantly higher in type 2 diabetic (T2DM) subjects that have ED compared with those that do not. Mahbub et al. found that the use of diuretic drugs was significantly associated with erectile dysfunction in these subjects [10] [17].

Ugwu et al. in Nigeria found significant positive association between PAD, $\mathrm{HbA1c}$ level, longer duration of DM and ED but there was no significant association between waist circumference (WC), systemic hypertension and erectile dysfunction [18].

There were conflicting findings about some of the correlates of ED in T2DM subjects from a lot of studies done in different parts of the world. Also, there were few studies that evaluated the association between peripheral artery disease especially and some of the other risk factors for ED in T2DM subjects in the Sub-Saharan Africa and the South-eastern Nigeria particularly. This study was aimed at determining the correlation between ED and glycaemic control, duration of DM, obesity, PAD, hypertension and antihypertensive medications use respectively.

\section{Materials and Methods}

This study was a cross sectional one carried out at the diabetes clinic of the Nnamdi Azikiwe University Teaching Hospital (NAUTH), Nnewi, Anambra State, Nigeria. The study population consisted of male T2DM subjects aged 30 years and above respectively from Anambra State and the neighbouring states that patronize the hospital.

Ethical clearance was obtained from the ethics committee of the Nnamdi Azikiwe University Teaching Hospital, Nnewi before the commencement of the study. 
A convenience sampling method was used whereby the study subjects were met individually by the researcher as they presented consecutively at the diabetes clinic. The patients who met the study inclusion criteria and had none of the exclusion criteria were recruited and completed the study.

Males with T2DM aged 30 years and above who gave written consent were eligible for the study. A patient was excluded from the study if he had type $1 \mathrm{DM}$, a history of pelvic/penile trauma or surgery, hypogonadism, a history of psychiatric illness, including anxiety and depression or anti-psychotic medication use, unfavourable penile anatomy for sexual act, urinary tract infection or was severely ill.

The researcher had two contacts with each of the study subjects. At the first meeting the subjects who met the eligibility criteria and did not have any of the exclusion criteria were guided to fill the Hospital Anxiety and Depression Scale (HADS) questionnaires for the diagnosis of depression or anxiety [19]. The participants without anxiety or depression were given another appointment between 8 and 10 o'clock in the morning after an overnight fast of about $10-12$ hours for biochemical investigations including fasting plasma glucose (FPG), HbA1c and serum total testosterone.

Next, a detailed physical examination, blood pressure and anthropometric measurements and vascular assessment with a hand-held doppler ultrasound were carried out. Then a pre-tested investigator-structured study proforma and an International Index of Erectile Function questionnaire (IIEF) were administered to the participants [20]. The contents of the questionnaires were translated into vernacular for participants who could not understand English language and their responses were filled in appropriately by the researcher. The study proforma was used to obtain the medical and drug history while the IIEF questionnaire was for the diagnosis of erectile dysfunction. A total of 48 subjects had hypogonadism and were dropped from the study while 124 participants completed the study.

Blood samples for the laboratory assays were obtained via venepuncture. Samples for FBG were collected in fluoride oxalate bottles and analysed by the Trinder glucose oxidase method. The samples for HbAlc were collected in EDTA bottles and analysed with the boronate affinity chromatography method using the automated CLOVER A1c Analyzer (Infopia, Korea) and CLOVER A1c Self-Test Cartridge. The blood samples for total testosterone assay were collected in plain bottles and were measured by radioimmunoassay (RIA) using Testosterone ELISA Immunoassay kits (BioCheck) - BC - 1115.

Doppler ultrasonography of the brachial, dorsalis pedis and posterior tibial arteries were done using EDAN SONOTRAX Ultrasonic Pocket Doppler version 1.2 (CE 0123) with $8.0 \mathrm{MHz}$ probe and an Accoson mercury Sphygmomanometer. Ankle brachial pressure index was calculated using the formula:

$$
\text { ABPI for a leg }=\frac{\text { Higher pressure obtained from the ankle vessels in that leg }}{\text { Higher brachial pressures of the } 2 \text { arms }}
$$


The subjects in this study were first divided into 2 groups based on the duration of diabetes: those with duration less than 5 years and those with duration of 5 years and above and subsequently into 0 - 5 years, 6 - 10 years, 11 - 15 years, 16 - 20 years and 21 - 25 years for statistical analysis.

\section{Statistical Analysis}

All the data were analysed using the Statistical Package for the Social Sciences (SPSS) version 20 (Chicago, IL, USA). Descriptive statistics which included frequency, percentage, means and standard deviations were used to summarize categorical and continuous variables. Associations between categorical variables were done using Chi-square test and logistic regression. Student's t-test was used to compare means of continuous variables. Level of significance was set at $\mathrm{P}<$ 0.05. Results were presented in tables.

\section{Definition of Terms and Criteria}

- Erectile dysfunction (ED) was diagnosed with a score of $\leq 25$ in the IIEF Questionnaire [20].

- Mild ED is a score of $17-25$ on the IIEF, moderate ED is $11-16$ and severe $\mathrm{ED}$ is $6-10[20]$.

- Poor glycaemic control was taken as $\mathrm{HbA1C} \geq 7.0 \%$ [5].

- Global obesity was defined by body mass index (BMI) $>30\left(\mathrm{~kg} / \mathrm{M}^{2}\right)[5]$.

- Central obesity (Abdominal obesity) was defined as waist circumference (WC) and waist to hip ratio (WHR) values $>92.90$ and 0.92 respectively [22].

- Peripheral artery disease was defined by an ankle brachial pressure index (ABPI) value of $\leq 1.0$ [22].

- Hypogonadism was taken as morning serum total testosterone level $<280$ $\mathrm{ng} / \mathrm{dl}(9.70 \mathrm{nmol} / \mathrm{l})[23]$.

- Anxiety was defined by a score on the HADS Anxiety Scale of $\geq 8$ [19].

- Depression was defined by a score on the HADS Depression Scale of $\geq 8$ [19].

- Diabetes mellitus was defined by fasting plasma glucose of $\geq 7.0 \mathrm{mmol} / \mathrm{l}$ (126 $\mathrm{mg} / \mathrm{dl}$ ) measured on at least 2 separate occasions or patient is already on glucose lowering agents [5].

- Type 1 DM was defined as subjects with DM who are dependent on insulin for survival and are at risk for ketoacidosis [5].

- Type $2 \mathrm{DM}$ was defined as patients with DM on diet therapy either alone or in combination with oral glucose lowering agent(s) for glycaemic control [5].

- Hypertension was defined as systolic BP $\geq 140 \mathrm{mmHg}$ and or diastolic $\mathrm{BP} \geq$ $90 \mathrm{mmHg}$ measured on at least 2 separate occasions or if patient is already on antihypertensive medications [24].

- Young age was taken as 18 - 44 years, middle age as 45 - 64 years and old age as 65 years and above [25].

\section{Results}

A total of 124 patients were studied. The prevalence rate of ED among the subjects was $48.4 \%$. 


\section{Characteristics of the study subjects}

The mean age of the subjects was $58.29 \pm 10.02$ years, and their mean IIEF score was $26.77 \pm 19.40$. They had a mean BMI of $26.89 \pm 4.22 \mathrm{~kg} / \mathrm{m}^{2}$ and a mean WC of $91.15 \pm 9.86 \mathrm{~cm}$. Their mean blood pressure at the time of study was $128.60 \pm 18.22 \mathrm{mmHg}$ for SBP and mean DBP was $84.16 \pm 12.64 \mathrm{mmHg}$. These and other clinical characteristics are shown in Table 1.

Association between Erectile dysfunction and its risk factors among the subjects

Table 2 shows that glycaemic control was significantly associated with ED among the subjects $(\mathrm{OR}=0.198,95 \% \mathrm{CI}=0.081-0.483, \mathrm{P}<0.001)$. Subjects with good glycaemic control were less likely to have ED compared with those with poor glycaemic control. Similarly, PAD was significantly associated with

Table 1. Baseline characteristics of study subjects.

\begin{tabular}{cc}
\hline Variables & $\begin{array}{c}\text { Mean }(\mathrm{SD}) \\
\text { Type 2 DM Subjects }(\mathbf{n}=\mathbf{1 2 4})\end{array}$ \\
\hline Age (years) & $58.29(10.02)$ \\
IIEF score & $26.77(19.40)$ \\
Weight $(\mathrm{kg})$ & $78.89(9.86)$ \\
Height $(\mathrm{m})$ & $1.70(0.08)$ \\
BMI $\left(\mathrm{kg} / \mathrm{m}^{2}\right)$ & $26.89(4.22)$ \\
WC $(\mathrm{cm})$ & $91.15(9.86)$ \\
WHR & $0.95(0.05)$ \\
SBP $(\mathrm{mmHg})$ & $128.60(18.22)$ \\
DBP $(\mathrm{mmHg})$ & $84.16(12.64)$ \\
Mean ABPI & $1.03(0.36)$ \\
FPG $(\mathrm{mmol} / \mathrm{L})$ & $9.01(3.19)$
\end{tabular}

ABPI = Ankle Brachial Pressure Index; BMI = Body Mass Index; DPB = Diastolic Blood Pressure; FPG = Fasting Plasma Glucose; IIEF = International Index of Erectile Function; SBP = Systolic Blood Pressure; WC $=$ Waist Circumference; WHR $=$ Waist to Hip Ratio.

Table 2. Association between erectile dysfunction and its risk factors among the subjects.

\begin{tabular}{cccc}
\hline & OR & $95 \%$ CI for OR & P value \\
\hline Glycaemic control & 0.198 & $0.081-0.483$ & $<0.001$ \\
Central Obesity (W/H ratio) & 0.915 & $0.416-2.014$ & 0.825 \\
Central Obesity (WC) & 0.599 & $0.294-1.219$ & 0.158 \\
Global Obesity & 0.532 & $0.228-1.239$ & 0.143 \\
Peripheral artery disease & 2.867 & $1.360-6.044$ & 0.006 \\
Antihypertensive use & 1.703 & $0.811-3.577$ & 0.160 \\
DM duration (years) & 0.566 & $0.253-1.268$ & 0.167 \\
$<5$ & & & \\
5 or more & & &
\end{tabular}


erectile dysfunction. Subjects with PAD were 3 times more likely to have erectile dysfunction $(\mathrm{OR}=2.867,95 \% \mathrm{CI}=1.360-6.044, \mathrm{P}=0.006)$. However, no significant associations were found between ED and variables like Obesity, antihypertensive medications use and duration of diabetes mellitus among subjects $(\mathrm{P}>0.05)$.

Association between DM duration and severity of erectile dysfunction among subjects

Table 3 shows that subjects with duration of diabetes below 15 years had higher occurrence of ED and its severity compared with those with duration of diabetes above 15 years although this association was not statistically significant $(\mathrm{P}=0.325)$.

\section{Correlation between obesity and erectile dysfunction in the subjects}

There was no significant correlation between global obesity and ED in the subjects $(\mathrm{OR}=0.532,95 \% \mathrm{CI}=0.228-1.239, \mathrm{P}<0.143)$. Also, $\mathrm{WC}$ and $\mathrm{W} / \mathrm{H}$ ratio (central obesity) did not have significant correlation with ED in the subjects $(\mathrm{OR}=0.599,95 \% \mathrm{CI}=0.294-1.219, \mathrm{P}<0.158$ and $\mathrm{OR}=0.915,95 \% \mathrm{CI}=0.416-$ $2.014, \mathrm{P}<0.825$ respectively).

Association between duration of hypertension and degree of erectile dysfunction in the subjects

Table 4 shows that 36 (46.75\%) type 2 diabetic subjects with hypertension had ED compared with $41(53.25 \%)$ that did not, although this difference was not statistically significant. Also, the number of hypertensive type 2 diabetic subjects that had ED appeared to be decreasing with increasing duration of hypertension. Severe ED was commoner among subjects with duration of hypertension of 5 years or less and this was equally not statistically significant $(\mathrm{P}=0.532)$.

Association between antihypertensive medications use and degree of erectile dysfunction in the subjects

Table 4 shows that all the 77 type $2 \mathrm{DM}$ subjects that have hypertension were on antihypertensive medications. $36(46.73 \%)$ of these subjects had ED while the remaining 41 (53.25\%) did not have erectile dysfunction. The difference is not statistically significant $(P=0.532)$. Out of the 36 subjects that had $E D, 9$ had mild, 3 had moderate and 24 had severe ED respectively.

Table 3. Association between duration of diabetes and severity of erectile dysfunction among subjects.

\begin{tabular}{|c|c|c|c|c|c|c|}
\hline \multicolumn{7}{|c|}{ N (\%) } \\
\hline \multirow{2}{*}{$\begin{array}{l}\text { DM Duration } \\
\text { (Years) }\end{array}$} & \multicolumn{4}{|c|}{ Type 2 DM Subjects $(\mathrm{N}=124)$} & \multirow[b]{2}{*}{$x^{2}$} & \multirow[b]{2}{*}{ P-value } \\
\hline & $\begin{array}{l}\text { Mild ED } \\
(n=16)\end{array}$ & $\begin{array}{l}\text { Moderate ED } \\
\quad(n=7)\end{array}$ & $\begin{array}{l}\text { Severe ED } \\
(n=37)\end{array}$ & $\begin{array}{c}\text { ED Absent } \\
(\mathrm{n}=64)\end{array}$ & & \\
\hline $0-5$ & $5(31.25)$ & $0(0.0)$ & $12(32.4)$ & $19(29.7)$ & 13.633 & 0.325 \\
\hline $6-10$ & $5(31.25)$ & $5(71.4)$ & $9(24.3)$ & $24(37.5)$ & & \\
\hline $11-15$ & $6(37.50)$ & $1(14.3)$ & $7(18.9)$ & $11(17.2)$ & & \\
\hline $16-20$ & $0(0.0)$ & $0(0.0)$ & $7(18.9)$ & $7(10.9)$ & & \\
\hline $21-25$ & $0(0.0)$ & $1(14.3)$ & $2(5.5)$ & $3(4.7)$ & & \\
\hline
\end{tabular}


Table 4. Association between duration of hypertension and degree of erectile dysfunction in the subjects.

\begin{tabular}{|c|c|c|c|c|c|c|}
\hline \multicolumn{7}{|c|}{ N (\%) } \\
\hline \multirow{3}{*}{$\begin{array}{l}\text { Hypertension } \\
\text { Duration } \\
\text { (Years) }\end{array}$} & \multirow{2}{*}{\multicolumn{4}{|c|}{$\begin{array}{c}\text { Type } 2 \text { DM Subjects with Hypertension }(\mathrm{N}=77) \\
\text { Type } 2 \text { DM Subjects with Hypertension and on } \\
\text { antihypertensive drugs }(\mathrm{N}=77)\end{array}$}} & \multirow{3}{*}{$x^{2}$} & \multirow{3}{*}{ P-value } \\
\hline & & & & & & \\
\hline & $\begin{array}{c}\text { Mild ED } \\
(\mathrm{n}=9)\end{array}$ & $\begin{array}{c}\text { Moderate ED } \\
(\mathrm{n}=3)\end{array}$ & $\begin{array}{c}\text { Severe ED } \\
(\mathrm{n}=24)\end{array}$ & $\begin{array}{c}\text { ED Absent } \\
(\mathrm{n}=41)\end{array}$ & & \\
\hline $0-5$ & $3(33.3)$ & $0(0.0)$ & $10(41.7)$ & $14(34.1)$ & 10.960 & 0.532 \\
\hline $6-10$ & $5(55.6)$ & $2(66.7)$ & $7(29.2)$ & $20(48.8)$ & & \\
\hline $11-15$ & $1(11.1)$ & $1(33.3)$ & $3(12.5)$ & $3(7.3)$ & & \\
\hline $16-20$ & $0(0.0)$ & $0(0.0)$ & $2(8.3)$ & $4(9.8)$ & & \\
\hline $21-25$ & $0(0.0)$ & $0(0.0)$ & $0(0.0)$ & $0(0.0)$ & & \\
\hline $26-30$ & $0(0.0)$ & $0(0.0)$ & $2(8.3)$ & $0(0.0)$ & & \\
\hline
\end{tabular}

\section{Discussion}

This study was a cross sectional hospital-based study which aimed at assessing the associations between ED and its correlates in T2DM subjects. The mean age of our participants is 58.29 (10.02) years and is comparable to 57.8 (13.2) years from Ugwumba et al. although older than 43.39 years from Seid et al. [26] [27].

Association between Glycaemic control and Erectile dysfunction in subjects

Glycaemic control has been consistently linked to significant inverse correlation with erectile dysfunction. This means that the risk of erectile dysfunction reduces with improving glycaemic control (decreasing $\mathrm{HbA1c}$ level) and increases with reduction in glycaemic control (increasing HbAlc). This finding was confirmed by this study and agrees with the studies done by Ugwu et al. and Ugwumba et al. in Nigeria [18] [26]. Similarly, studies done in Bangladesh and Saudi Arabia also found significant inverse association between glycaemic control and ED in men with type 2 diabetes mellitus [10] [13]. Binmoammar et al. in analyses of several works done on ED in men with TDM also found significant positive association between ED and glycaemic control [28].

Seid et al. on the other hand did not find significant association between glycaemic control and ED in Ethiopia [27].

Poor glycaemic control which results in chronic hyperglycaemia increases the risk of ED in DM subjects through four major hypothetical mechanisms that are linked to vasculopathy and neuropathy, which are the two main causes of diabetes-induced erectile dysfunction. Hyperglycaemia-induced damage to blood vessels and nerves occurs via increased polyol pathway flux, increased intracellular formation of advanced glycation end-products (AGEs), activation of protein kinase $\mathrm{C}$ and increased hexosamine pathway flux. All these are linked to over production of superoxide by the mitochondrial transport chain, which is 
both vasculopathic and neuropathic.

Association between Duration of Diabetes and Erectile dysfunction in subjects

The subjects in this study were first divided into 2 groups based on the duration of diabetes for analysis: those with duration less than 5 years and those with duration of 5 years and above and subsequently into 0 - 5 years, 6 - 10 years, 11 15 years, 16 - 20 years and $21-25$ years for statistical analysis. This study did not find a significant association between the duration of DM and ED and its severity grades in the study subjects, although more subjects with ED had duration of diabetes 5 years or longer. Of the 60 subjects that had ED, 13 (21.7\%) had duration of diabetes of less than 5 years, while $47(78.3 \%)$ had duration of DM of 5 years and above. Also, of the 64 subjects without ED, 21 (32.8\%) had duration of DM less than 5 years and $43(67.2 \%)$ had duration of diabetes of 5 or more years ( $\mathrm{OR}=0.566,95 \% \mathrm{CI}$ for $\mathrm{OR}=0.253-1.268, \mathrm{P}=0.167)$. Subjects with duration of diabetes below 15 years unexpectedly had a higher occurrence of ED and its' severity compared to those with duration of diabetes above 15 years. This finding agrees with those of Ugwu et al. and Mutagaywa et al. who equally did not find significant association between duration of T2DM and erectile dysfunction [18] [29]. On the other hand, a lot of works found positive association between duration of T2DM and erectile dysfunction [10] [26] [27] [28]. The differences in the findings could be due to differences in the methodology used and the population characteristics studied, and this included the population sizes, duration and severity of diabetes and the presence of other confounding co-morbidities.

It is possible that by screening out participants with low total testosterone from this study, a lot of subjects who had long duration of DM and diabetesinduced hypogonadism may have been dropped.

Also, the time of first diagnosis determines the duration of diabetes, therefore late diagnosis of T2DM in some of our participants could have influenced this result in view of the fact that it is very difficult to determine the exact time of the onset/duration of type 2 diabetes mellitus. A study had already found that about $36.3 \%$ of the subjects with type 2 diabetes had developed erectile dysfunction at the time of diagnosis [12]. Moreover, most subjects with longer duration of diabetes were more likely to have received treatment for erectile dysfunction and other chronic complications of DM at some points prior to this study.

Association between Obesity and Erectile dysfunction in subjects

This study found no significant association between both global obesity and central obesity and ED in the study subjects. Similarly, Meena et al. and Garg et al. found no significant association between BMI and WHR and ED in subjects with type 2 diabetes mellitus [17] [30]. Ugwu et al. did not find significant association between WC and ED in subjects with type 2 diabetes mellitus [18]. Seid et al. did not find significant association between BMI and ED in men with type 2 diabetes [27]. Similarly, Sharif et al. did not find significant association between obesity and ED in this group of subjects [31]. This finding however 
does not agree with some other ones that found significant association between obesity and erectile dysfunction [26] [28] [32]. Differences in the methodology adopted by some of the studies, as well as the characteristics of the population they studied could account for the differences in the findings.

Association between Peripheral artery disease and Erectile dysfunction in subjects

This study showed that PAD was significantly associated with ED in the subjects $(\mathrm{OR}=2.867,95 \% \mathrm{CI}$ for $\mathrm{OR}=1.360-6.044, \mathrm{P}=0.006)$. The presence of peripheral artery disease carried thrice greater risk of ED in the subjects. Ugwu et al., Thomas et al. and Mutagaywa et al. equally found that PAD was significantly associated with increased risk of ED in patients with type 2 diabetes mellitus [18] [14] [29]. Polonsky et al. had similar finding in the general population [33]. A study done in Spain did not find significant association between peripheral artery disease and ED in men with type 2 diabetes mellitus [15]. The differences in the methodology adopted, including the diagnostic tool for peripheral artery disease, could account for the different finding in Spain.

Association between Antihypertensive medications use and Erectile dysfunction in subjects

Another finding from this study was that the use of antihypertensive medications did not have significant association with the occurrence of ED in the study subjects. This is comparable to the finding from Bolm et al. [34]. Mahbub et al. found that the use of diuretic antihypertensive drugs is significantly associated with $\mathrm{ED}$ in type $2 \mathrm{DM}$ subjects [10]. Most of the subjects taking antihypertensive medications in this study were on ARBs or ACE inhibitors. Only a few subjects were on calcium channel blockers. Angiotensin receptor blockers had been reported in a study to have exhibited a beneficial effect on erectile function while calcium channel blockers (CCBs) and ACE inhibitors seem to have neutral effect [16]. A study conducted in the general population in Sweden found that ED was associated with the use of antihypertensive drugs except ACE inhibitors [35].

Association between Hypertension, Duration of hypertension and Erectile dysfunction in subjects

This study found that hypertension was not significantly associated with ED in T2DM subjects. The number of hypertensive T2DM subjects that had ED was less than those that did not have erectile dysfunction (46.75\% to $53.25 \%)(\mathrm{P}=$ 0.532).

There was also no significant association between the duration of hypertension and ED or duration of hypertension and the severity grades of ED in subjects studied. This finding is similar to that from several other studies [26] [27] [28] [36]. Bohm et al. did not find significant association between hypertension and ED in non-diabetic subjects [34]. The finding from this study is likely due to the fact that all the 77 hypertensive, T2DM subjects studied were either taking angiotensin receptor blockers or angiotensin converting enzyme inhibitors with 
or without other antihypertensive medications. Angiotensin receptor blockers have been reported to exhibit a beneficial effect on ED while angiotensin converting enzyme inhibitors seem to have neutral effect [16]. Also, the longer the duration of hypertension in these subjects, the more likely they were to be on these medications.

Meena et al. on the other hand found that systolic blood pressure was significantly higher in type 2 diabetic men with ED compared with those without erectile dysfunction [17]. Bener et al. found that prevalence of ED was significantly higher in hypertensive men than in normotensive men and that the duration of hypertension was significantly associated with ED in these men [37].

\section{Strengths of the Study}

Most works done on ED in diabetes did not exclude men with low serum testosterone level. Hypogonadism is a notable cause of ED and can result from so many other causes other than diabetes mellitus. This can be a confounder in establishing the real burden of diabetes-induced erectile dysfunction. Similarly, most works on the correlates of ED in men with T2DM did not screen for peripheral artery disease. This is coupled with the fact that there is paucity of data on the risk factors for ED in men with T2DM in the Sub-Saharan Africa. This work attempted to contribute to the existing knowledge on this very important topic.

\section{Limitations}

International Index of Erectile Function (IIEF) questionnaire used in this study is a self-report diagnostic tool. Its interpretation to the patients who do not understand English language may have reduced the accuracy of the responses given.

Subjects who are diabetic and hypertensive and/or on antihypertensive medications were not excluded from the study as this would have limited the number of subjects used for the study.

The Hospital Anxiety and Depression Scale questionnaire also used in the study is a self-report diagnostic tool. Its interpretation to the patients who do not understand English language may have reduced the accuracy of the responses given. Also, the socio-cultural implications of some of the questions in our setting could make some of the responses very subjective.

The cross-sectional nature of this study did not allow the researchers make inference about cause and effect of the risk factors of ED in population studied.

\section{Conclusion}

There is significant correlation between glycaemic control, peripheral artery disease and ED in Nigerian men with type 2 diabetes mellitus. There is no significant correlation between ED and the duration of diagnosis of diabetes mellitus, obesity (global and central), antihypertensive medication use and duration of hypertension. 


\section{What Is Known about This Topic}

Erectile dysfunction is a very common complication of diabetes that is grossly under reported and is associated with a poor quality of life. It is also rarely sought for and treated by health care professionals during diabetes consultations. Some of its risk factors in the setting of T2DM are very much treatable and occasionally reversible with early intervention.

\section{What This Study Adds to the Topic}

This study found that glycaemic control and peripheral artery disease are strong predictors of erectile dysfunction in men with type 2 diabetes. Currently peripheral artery disease is not routinely screened for in our diabetes clinics despite the fact that it can be done at the bed side using a hand-held doppler ultrasound. This work apart from stimulating further studies on this important topic will also create more awareness for early screening for peripheral artery disease and glycaemic control in our diabetic patients and the holistic treatment of diabetes.

\section{Acknowledgements}

I wish to acknowledge Mr Ikenna and Dr Nnadozie for assisting with the data and biochemical analysis respectively.

\section{Ethical Approval}

Ethical approval was obtained from the Ethics Committee of Nnamdi Azikiwe University Teaching Hospital Nnewi.

\section{Authors' Contributions}

Author CME conceptualized/designed the study, involved in data collection, analysis, interpretation and drafting of manuscript, Author AME; involved in data collection/cleaning, literature review and aspects of initial manuscript draft, Author EEY; involved in data analysis and interpretation, Author OCO; supervision of the research and manuscript writing, Author AGB; overall supervision of the research. All the authors read, edited and approved the manuscript.

\section{Conflicts of Interest}

The authors declare no conflicts of interest regarding the publication of this paper.

\section{References}

[1] NIH Consensus Conference (1993) Impotence. NIH Consensus Development Panel on Impotence. JAMA, 270, 83-90. https://doi.org/10.1001/jama.1993.03510010089036

[2] De Berardis, G., Francoisi, M., Belfiglio, M., Di Nardo, B., Greenfield, S., Kaplan, S.H., et al. (2002) Erectile Dysfunction and Quality of Life in Type 2 Diabetic Patients. Diabetes Care, 25, 284-291. https://doi.org/10.2337/diacare.25.2.284 
[3] Neelima, V.C. and Edelman, S.V. (2001) Diabetes and Erectile Dysfunction. Clinical Diabetes, 15, 63-71.

[4] Idung, A.U., Abasiubong, F., Ukott, I.A., Udoh, S.B. andUnadike, B.C. (2012) Prevalence and Risk Factors of Erectile Dysfunction in Niger Delta Region, Nigeria. African Health Sciences, 12, 160-165. https://doi.org/10.4314/ahs.v12i2.13

[5] World Health Organization (1999) Definition, Diagnosis and Classification of Diabetes Mellitus and Its Complications. WHO/NCD/NCS 99. Geneva, 1-58.

[6] UK Prospective Diabetes Study (UKPDS) Group (1998) Intensive Blood-Glucose Control with Sulphonylureas or Insulin Compared with Conventional Treatment and Risk of Complications in Patients with Type 2 Diabetes (UKPDS 33). The Lancet, 352, 837-853. https://doi.org/10.1016/S0140-6736(98)07019-6

[7] Diabetes Control and Complication Trial Research Group (1993) The Effect of Intensive Treatment of Diabetes on the Development and Progression of Long-Term Complications in Insulin-Dependent Diabetes Mellitus. The New England Journal of Medicine, 329, 977-986. https://doi.org/10.1056/NEJM199309303291401

[8] Owiredu, W., Amidu, N., Alidu, H., Sarpong, C. and Gyasi-Sarpong, C.K. (2011) Determinants of Sexual Dysfunction among Clinically Diagnosed Diabetic Patients. Reproductive Biology and Endocrinology, 9, 70. https://doi.org/10.1186/1477-7827-9-70

[9] Ahmed, I., Aamir, A., Anwar, E., Ali, S. and Ali, A. (2013) Erectile Dysfunction and Type 2 Diabetes in Northern Pakistan. JPMA, 12, 1486-1490.

[10] Mahbub, M.I., Kamrul-Hassan, A.B., Salim, S., Mir, A.S., Saifuddin, M. and Pathan, M.F. (2019) Frequency and Predictors of Eerctile Dysfunction in Bangladeshi Men with Type 2 Diabetes Mellitus: Experience from a Tertiary Center. Mymensingh Medical Journal, 28, 137-143.

[11] Esposito, K., Giugliano, F., Clotola, M., De sio, M., D’Armiento, M. and Giugliano, D. (2008) Obesity and Sexual Dysfunction, Male and Female. International Journal of Impotence Research, 20, 358-365. https://doi.org/10.1038/ijir.2008.9

[12] Giugliano, F., Maiorino, M., Bellastella, G., Gicchino, M., Giugliano, D. and Esposito, K. (2010) Determinants of Erectile Dysfunction in Type 2 Diabetes. International Journal of Impotence Research, 22, 204-209. https://doi.org/10.1038/ijir.2010.1

[13] Almigbal, T.H. (2019) Erectile Dysfunction in Men with Type 2 Diabetes: Is It Associated with Poor Glycaemic Control? Journal of Men's Health, 15, e12-e22. https://doi.org/10.22374/jomh.v15i1.104

[14] Thomas, G.N., Tomlinson, B., Abdullah, A.S., Yeung, D.T., Chan, J.C.N. and Wong K.S. (2005) Association of Erectile Dysfunction with Cardiovascular Risk Factors and Increasing Existing Vascular Disease in Male Chinese Type 2 Diabetic Patients. Diabetes Care, 28, 2051-2053. https://doi.org/10.2337/diacare.28.8.2051

[15] Garcia-Malpartida, K., Marmol, R., Jover, A., Gomez-Martinez, M., Sola-Izquierdo, E., Victor, V.M., et al. (2011) Relationship between Erectile Dysfunction and Silent Myocardial Ischemia in Type 2 Diabetic Patients with No Known Macrovascular Complications. The Journal of Sexual Medicine, 8, 2606-2616. https://doi.org/10.1111/j.1743-6109.2011.02365.x

[16] Doumas, M. and Doumas, S. (2006) The Effect of Antihypertensive Drugs on Erectile Function: A Proposed Management Algorithm. Journal of Hypertension, 8, 359-363. https://doi.org/10.1111/j.1524-6175.2005.05285.x

[17] Meena, B.L., Kocher, D.K., Agarwal, T.D., Choudhary, R. and Kocher, A. (2009) Association between Erectile Dysfunction and Cardiovascular Risk in Individuals 
with Type-2 Diabetes without Overt Cardiovascular Disease. International Journal of Diabetes in Developing Countries, 29, 150-154.

https://doi.org/10.4103/0973-3930.57345

[18] Ugwu, T., Ezeani, I., Onung, S., Kolawale, B. and Ikem, R. (2016) Predictors of Erectile Dysfunction in Men with Type 2 Diabetes Mellitus Refered to a Tertiary Healthcare Centre. Advances in Endocrinology, 2016, Article ID: 9753154. https://doi.org/10.1155/2016/9753154

[19] Zigmond, A.S. and Snaith, R.P. (1983) The Hospital Anxiety and Depression Scale. Acta Psychiatrica Scandinavica, 67, 361-370. https://doi.org/10.1111/j.1600-0447.1983.tb09716.x

[20] Rosen, R.C., Cappelleri, J.C., Smith, M.D., Lipsky, J. and Pena, B.M. (1999) Development and Evaluation of an Abridged, 5-Item Version of the International Index of Erectile Function (IIEF) as a Diagnostic Tool for Erectile Dysfunction. International Journal of Impotence Research, 11, 319-326.

https://doi.org/10.1038/sj.ijir.3900472

[21] McNeely, M.J., Boyko, E.J., Ahroni, J.H., Stensel, V.L., Reiber, S.E., Smith, D.G., et al. (1995) The Independent Contribution of Diabetic Neuropathy and Vasculopathy in Foot Ulceration: How Great Are the Risks? Diabetes Care, 18, 216-219. https://doi.org/10.2337/diacare.18.2.216

[22] Clinical Laboratory Standards Institute, National Committee for Clinical Laboratory Standards (2000) How to Define and Determine Reference Intervals in the Clinical Laboratory: Approved Guideline. C28-A2. CLSI/NCCLS, Wayne.

[23] Bhasin, S., Cunningham, G.R., Hayes, F.J., Matsumoto, A.M., Synder, P.J., Swerdloff, R.S., et al. (2006) Testosterone Therapy in Adult Men with Androgen Deficiency Syndromes: An Endocrine Society Clinical Practice Guideline. The Journal of Clinical Endocrinology and Metabolism, 91, 1995-2010. https://doi.org/10.1210/jc.2005-2847

[24] Chobanian, A.V., Bakris, G.L., Black, H.R., Cushman, W.C., Green, L.A., Izzo, J.L., et al. (2003) Seventh Report of the Joint National Committee on Prevention, Detection, Evaluation, and Treatment of High Blood Pressure. Hypertension, 42, 1206-1252. https://doi.org/10.1161/01.HYP.0000107251.49515.c2

[25] U.S. Census Bureau (2012) Population Estimates and 2012 National Projections. https://www.census.gov

[26] Ugwumba, F.O., Okafor, C.I., Nnabugwu, I.I., Udeh, E.I., Echetabu, K.N., Okoh, A.D., et al. (2018) Prevalence of, and Risk Factors for Erectile Dysfunction in Male Type 2 Diabetic Outpatient Attendees in Enugu, South East Nigeria. Annals of African Medicine, 17, 215-220. https://doi.org/10.4103/aam.aam 318 http://www.annalsafrmed.org/text.asp?2018/17/4/215/248393

[27] Seid, A., Gerensea, H., Tarko, S., Zenebe, Y. and Mezemir, R. (2017) Prevalence and Determinants of Erectile Dysfunction among Diabetic Patients Attending a Hospital of Central and Northern Zone of Tigray, Northern Ethiopia: A Cross Sectional Study. BMC Endocrine Disorders, 17, 16. https://doi.org/10.1186/s12902-017-0167-5

[28] Binmoammar, T.A., Hassounah, S., Alsaad, S., Rawaf, S. and Majeed, A. (2016) The Impact of Poor Glycaemic Control on the Prevalence of Erectile Dysfunction in Men with Type 2 Diabetes Mellitus: A Systemic Review. JRSM Open, 7, 1-10. https://doi.org/10.1177/2054270415622602

[29] Mutagaywa, R.K., Lutale, J., Aboud, M. and Kamala, B.A. (2014) Prevalence of Erectile Dysfunction and Associated Factors among Diabetic Men Attending Diabetic 
Clinic at Muhimbili National Hospital in Dar-es-Salaam, Tanzania. The Pan African Medical Journal, 17, 227. https://doi.org/10.11604/pamj.2014.17.227.2695

[30] Garg, S., Rijhwani, P., Gupta, D., Khandelwal, M., Kumar, K. and Gupta, R. (2013) Study of Erectile Dysfunction in Type 2 Diabetic Patients. IJHBR, 1, 210-216.

[31] Sharif, F., Asghari, M., Jaberi, Y., Salehi, O. and Mirzamohammadi, F. (2012) Independent Predictors of Erectile Dysfunction in Type 2 Diabetes Mellitus: Is It True What They Say about Risk Factors? ISRN Endocrinology, 2012, Article ID: 502353. https://doi.org/10.5402/2012/502353

[32] Goyal, A., Singh, P. and Ahuja, A. (2013) Prevalence and Severity of Erectile Dysfunction as Assessed by IIEF-5 in North Indian Type 2 Diabetic Males and Its Correlation with Variables. Journal of Clinical and Diagnostic Research, 7, 2936-2938. https://doi.org/10.7860/JCDR/2013/7718.3777

[33] Polonsky, T.S., Taillon, L.A., Sheth, H., Min, J.K., Archer, S.L. and Ward, R.B. (2009) The Association between Erectile Dysfunction and Periheral Artery Disease as Determined by Screening Ankle-Brachial Index Testing. Atherosclerosis, 207, 440-444. https://doi.org/10.1016/j.atherosclerosis.2009.05.005

[34] Bohm, M., Baumhakel, M., Probstfield, J.L., Schmieder, R., Yusuf, S., Zhao, F., et al. (2007) Sexual Function, Satisfaction, and Association of Erectile Dysfunction with Cardiovascular Disease and Risk Factors in Cardiovascular High-Risk Patients: Substudy of the Ongoing Telmisartan Alone and in Combination with Ramipril Global Endpoint Trial/Telmisartan Randomized Assessment Study in ACE-Intolerant Subjects with Cardiovascular Disease (Ontarget/Transcend). American Heart Journal, 154, 94-101. https://doi.org/10.1016/j.ahj.2007.03.024

[35] Ekman, E., Hagg, S., Sundstrom, A. and Werkstrom, V. (2010) Antihypertensive Drugs and Erectile Dysfunction as Seen in Spontaneous Reports, with Focus on Angiotensin 2 Type 1 Receptor Blockers. Drug, Healthcare and Patient Safety, 2, 21-25. https://doi.org/10.2147/DHPS.S8432

[36] Severo, M.D., Leira, L.F., LedurPdos, S., Becker, A.D., Aquiar, F.M., Massierer, D., et al. (2014) Association between Erectile Dysfunction and Echocardiographic Variables of Ventricular Hypertrophy and Diastolic Function in Hypertensive Patients with Type 2 Diabetes Mellitus: A Cross Sectional Study. Journal of Diabetes, 6, 586-594. https://doi.org/10.1111/1753-0407.12133

[37] Bener, A., Al-Ansari, A., Al-Hamaq, A.O., Elbagi, I.E. and Afifi, M. (2007) Prevalence of Erectile Dysfunction among Hypertensive and Non-Hypertensive Qatari Men. Medicina (Kaunas), 43, 870-878. https://doi.org/10.3390/medicina43110112 


\section{Appendix 1}

Study proforma for the correllates of erectile dysfunction in patients with type 2 diabetes mellitus at Nnamdi Azikiwe University Teaching Hospital (Nauth), Nnewi.

Code:

1. Age: (years)

2. Do you have diabetes mellitus?: Yes [ ], No [ ]

3. If yes, what is the duration? (years)

4. What treatment do you take for diabetes mellitus? :

a- Diet alone [ ]

b- Diet + Oral glucose lowering agent(s) [

c- Diet + Oral glucose lowering agent(s) + Insulin [

d- Others (Specify)

5. Do you suffer from hypertension?: Yes [ ], No [ ]

6. If yes, what is the duration? (years)

7. Are you taking drugs for hypertension? Yes [ ] No [ ]

8. Are you taking any drug for psychosis, depression or anxiety?

Yes [ ] No [ ]

9. Have you had surgery or trauma involving the spine, pelvis/prostate or penile?

Yes [ ] No [ ]

\section{Physical Examination}

1. Lower limb peripheral pulses:

a. Femoral artery pulsation:

Full volume [ ], Diminished volume [ ], Absent [ ]

b. Popliteal artery pulsation: Full volume [ ]

], Diminished volume [ ], Absent [

c. Dorsalis pedia artery pulsation:

Full volume [ ]

], Diminished volume [ ], Absent [

d. Posterior tibial artery pulsation:

Full volume [ ], Diminished volume [

], Absent [

2. BP with Doppler: Systolic Blood Pressure:

3. Ankle Brachial Index $=($ Right $)$ Ankle $\mathrm{SBP} \div$ Higher Arm SBP $=$

4. Peripheral artery disease:

5. BP with Syphgmomanometer:

6. Weight:

7. Height:

8. Body Mass Index (BMI):

9. Waist Circumference:

10. Hip Circumference:

11. Waist-Hip ratio:

12. Global obesity:

13. Central obesity:

Urogenital Examination:

14. Presence of sparse pubic hairs: Yes

15. Presence of microphallus:

16. Presence of epispadias:

17. Presence of hypospadias:
Yes

Systolic BP $(\mathrm{Kg})$

(M)

$\left(\mathrm{Kg} / \mathrm{M}^{2}\right)$

$(\mathrm{Cm})$

(Cm)

No

Diastolic BP 


\section{Laboratory Tests}

1. $\mathrm{HbA}_{1 \mathrm{C}}$ :

2. FPG: $(\mathrm{mmol} / \mathrm{L})$

3. Serum Total Testosterone: $(\mathrm{mmol} / \mathrm{L})$

\section{Appendix 2}

Individual items from the international index of erectile function (IIEF) questionnaire and response options. Circle the most appropriate Response option for each question.

\section{Question}

\section{Response options}

(All questions are preceded by "Over the past 4 weeks")

1. How often were you able to get an erection during sexual activity?

$$
\begin{aligned}
& 0=\text { No sexual activity } \\
& 1=\text { Almost never/never } \\
& 2=\text { A few times (much less than half the time) } \\
& 3=\text { Sometimes (about half the time) } \\
& 4=\text { Most times (much more than half the time) } \\
& 5=\text { Almost always/always }
\end{aligned}
$$

2. When you had erections with sexual stimulation, how often were your erections hard enough for penetration?

$$
\begin{aligned}
& 0=\text { No sexual activity } \\
& 1=\text { Almost never/never } \\
& 2=\text { A few times (much less than half the time) } \\
& 3=\text { Sometimes (about half the time) } \\
& 4=\text { Most times (much more than half the time) } \\
& 5=\text { Almost always/always }
\end{aligned}
$$

3. When you attempted sexual intercourse, how often were you able to penetrate (enter) your partner?

$$
\begin{aligned}
& 0=\text { Did not attempt intercourse } \\
& 1=\text { Almost never/never } \\
& 2=\text { A few times (much less than half the time) } \\
& 3=\text { Sometimes (about half the time) } \\
& 4=\text { Most times (much more than half the time) } \\
& 5=\text { Almost always/always }
\end{aligned}
$$

4. During sexual intercourse, how often were you able to maintain your erection after you had penetrated (entered) your partner?

$$
\begin{aligned}
& 0=\text { Did not attempt intercourse } \\
& 1=\text { Almost never/never } \\
& 2=\text { A few times (much less than half the time) } \\
& 3=\text { Sometimes (about half the time) } \\
& 4=\text { Most times (much more than half the time) } \\
& 5=\text { Almost always/always }
\end{aligned}
$$

5. During sexual intercourse, how difficult was it to maintain your erection to completion of intercourse?

$$
\begin{aligned}
& 0=\text { Did not attempt intercourse } \\
& 1=\text { Extremely difficult } \\
& 2=\text { Very difficult }
\end{aligned}
$$




$$
\begin{aligned}
& 3=\text { Difficult } \\
& 4=\text { Slightly difficult } \\
& 5=\text { Not difficult }
\end{aligned}
$$

6. How many times have you attempted sexual intercourse?

$$
\begin{aligned}
& 0=\text { No attempts } \\
& 1=\text { One to two attempts } \\
& 2=\text { Three to four attempts } \\
& 3=\text { Five to six attempts } \\
& 4=\text { Seven to ten attempts } \\
& 5=\text { Eleven }+ \text { attempts }
\end{aligned}
$$

7. When you attempted sexual intercourse, how often was it satisfactory for you?

$0=$ Did not attempt intercourse

$1=$ Almost never/never

$2=\mathrm{A}$ few times (much less than half the time)

$3=$ Sometimes (about half the time)

$4=$ Most times (much more than half the time)

$5=$ Almost always/always

8. How much have you enjoyed sexual intercourse?

$$
\begin{aligned}
& 0=\text { No intercourse } \\
& 1=\text { No enjoyment } \\
& 2=\text { Not very enjoyable } \\
& 3=\text { Fairly enjoyable } \\
& 4=\text { Highly enjoyable } \\
& 5=\text { Very highly enjoyable }
\end{aligned}
$$

9. When you had sexual stimulation or intercourse, how often did you ejaculate?

$$
\begin{aligned}
& 0=\text { No sexual stimulation/intercourse } \\
& 1=\text { Almost never/never } \\
& 2=\text { A few times (much less than half the time) } \\
& 3=\text { Sometimes (about half the time) } \\
& 4=\text { Most times (much more than half the time) } \\
& 5=\text { Almost always/always }
\end{aligned}
$$

10. When you had sexual stimulation or intercourse, how often did you have the feeling of orgasm or climax?

$1=$ Almost never/never

$2=$ A few times (much less than half the time)

$3=$ Sometimes (about half the time)

$4=$ Most times (much more than half the time)

$5=$ Almost always/always

11. How often have you felt sexual desire?

$$
\begin{aligned}
& 1=\text { Very low/none at all } \\
& 2=\text { Low } \\
& 3=\text { Moderate } \\
& 4=\text { High } \\
& 5=\text { Very high }
\end{aligned}
$$


12. How would you rate your level of sexual desire?

$$
\begin{aligned}
& 1=\text { Very dissatisfied } \\
& 2=\text { Moderately dissatisfied } \\
& 3=\text { About equally satisfied and dissatisfied } \\
& 4=\text { Moderately satisfied } \\
& 5=\text { Very satisfied }
\end{aligned}
$$

13. How satisfied have you been with your overall sex life?

$$
\begin{aligned}
& 1=\text { Very low } \\
& 2=\text { Low } \\
& 3=\text { Moderate } \\
& 4=\text { High } \\
& 5=\text { Very high }
\end{aligned}
$$

14. How satisfied have you been with your sexual relationship with your partner?

$$
\begin{aligned}
& \text { I }=\text { Very low } \\
& 2=\text { Low } \\
& 3=\text { Moderate } \\
& 4=\text { High } \\
& 5=\text { Very high }
\end{aligned}
$$

15. How do you rate your confidence that you could get and keep an erection?

$$
\begin{aligned}
& 1=\text { Very low } \\
& 2=\text { Low } \\
& 3=\text { Moderate } \\
& 4=\text { High } \\
& 5=\text { Very high }
\end{aligned}
$$

Total Score $=$

$\begin{array}{ll}\text { No ED } & =\text { Score of } \geq 26 \\ \text { ED } & =\text { Score of } \leq 25 \\ \text { Mild ED } & =17-25 \\ \text { Moderate ED } & =11-16 \\ \text { Severe ED } & =6-10\end{array}$

\section{Appendix 3}

\section{Hospital anxiety and depression scale (HADS)}

This questionnaire has been designed to help you explain to your clinicians how you have been feeling.

Read each item below and indicate which comes closest to how you have been feeling in the past week. Ignore the numbers printed at the side. Don't take too long over your replies; your immediate reaction to each item will probably be more accurate than a long, thought-out response.

\section{Depression Scale}

\section{A. Still enjoying the things i used to enjoy:}
0 - Definitely as much
1- Not quite so much now
2- Only a little
3- Hardly at all

\section{B. I can laugh and see the funny side of things:}

0 - As much as I always could

2- Definitely not so much now
1- Not quite so much now

3- Not at all 


\section{I feel cheerful:}

0 - most of the time

1- Some times

2- Not often

3-Never

D. I feel as if I am slowed down:
0 - Not at all
1- Sometimes

2- Very often

3- Nearly all the time

E. I have lost interest in my appearance:

0 - I take just as much care as ever

1- I may not take quite as much care

2- I don't take as much care as I should

3- Definitely $\square$

F. I look forward with enjoyment to things:

0 - As much as I ever did $\square$

1- Rather less than I used to

2- Definitely less than I used to

3- Hardly at all

G. I can enjoy a good book or radio or television programme:
0 - Often
1- Sometimes
2- Not often
3- Seldom

Total Scoring:

$<8=$ No Depression

$>8=$ Depression

\section{Anxiety Scale}

A. I feel tense or "wound up":
0 - Not at all
1- From time to time, occasionally
2- A lot of the time
3- Most of the time

B. I get a sort of frightened feeling as if something awful is about to happen:
0 - Not at all
1- A little but it doesn't worry me
2- Yes, but not too badly
3- Very definitely and quite badly

C. Worry thoughts go through my mind:
0 - Only occasionally
1- From time to time but not too often
2- A lot of the time
3- A great deal of the time

D. I can sit at ease and feel relaxed:
0 - Definitely
1- Usually
2- Not often

3- Not at all

E. I get a sort of frightened feeling like 'butterflies' in the stomach: 0 - Not at all 1- Occasionally

2- Quite often

3- Very often

F. I feel restless as if I have to be on the move: 0 - Not at all $\square$ 1- Not very much

2- Quite a lot

3- Very much indeed

G. I get sudden feeling of panic:

0 - Not at all

1- Not very often

2- Quite often

3- Very often indeed

\section{Total Score:}

$<8=$ No Anxiety

$>8=$ Anxiety 